\title{
Sex Ratio at Birth in a Tertiary Care Hospital in Western Nepal are the Trends Changing?
}

\author{
Aryal S ${ }^{1}$, Kalakheti $\mathbf{B}^{2}$
}

${ }^{1}$ Dr. Shreyashi Aryal, Lecturer, Department of Obstetrics and Gynaecology, ${ }^{2} \mathrm{Dr}$. Balkrishna Kalakheti, Associate Professor, Department of Paediatrics, Lumbini Medical College Teaching Hospital, Palpa, Nepal.

\author{
Address for correspondence: \\ Dr. Shreyashi Aryal, Lecturer \\ Department of Obstetrics and Gynaecology, \\ Lumbini Medical College Teaching Hospital, \\ Palpa Nepal. \\ Tel: +977-9813595444 \\ E-mail: shreyashiaryal@gmail.com
}

Acknowledgements: None

Funding: Nil

Conflict of Interest: None

Permission from IRB: Yes

Ethical dilemmas faced during study: None

\section{How to cite}

Aryal S, Kalakheti B. Sex Ratio at Birth in a Tertiary Care Hospital in Western Nepal are the Trends Changing?. J Nepal Paediatr Soc 2016;36(1):68-71.

doi: http://dx.doi.org/10.3126/jnps.v36i1.15086

This work is licensed under a Creative Commons Attribution 3.0 License.

\begin{abstract}
Introduction: Sex ratio at birth remains unchanged in absence of human intervention. A tendency of skewing towards males is seen in Asian population attributable to various reasons, foremost being abortions. The decreasing number of female population is a form of gender discrimination and has serious implications for both sexes in the future. The purpose of this study was to analyze the trends of sex ratio at birth among deliveries at Lumbini Medical College Teaching Hospital, Palpa, Nepal over the past eight years. Materials and Methods: A retrospective audit of deliveries from $1^{\text {st }}$ January 2008 to $31^{\text {st }}$ December 2015 was carried out. Sex ratio at birth was calculated and its relationship with maternal age, birth order and number of previous abortions was analyzed. Results: The total number of live-births during the study period was 9394 consisting of 5008 male and 4350 female with an overall sex ratio at birth of 112.6. Every year, there was an increasing trend in total number of live births and sex ratio at birth. The number of male births increased with increase in parity but there was no statistical difference seen between maternal age, parity and number of abortions for male and female births. Conclusion: The sex ratio at birth in hospital deliveries is unbalanced with inclination towards male, more so in women with high parity. Additional research exploring the reason for increase in male births is needed, so that potential programs which can reverse this trend can be implemented.
\end{abstract}

Key words: Abortion, Maternal age, Parity, Sex ratio

\section{Introduction}

ex ratio at birth (SRB) is defined as number of male live births for every 100 female births ${ }^{1}$. Under biological norms, birth ratio worldwide ranges from 102 to 106 boys born for every 100 girls and in absence of human intervention, it remains the same without changing even over a century ${ }^{2}$. Studies in Asian population, however, show a dynamic change with a skewing towards male $e^{3,4,5}$. Increased SRB is seen after 2005 which has been linked most commonly with sex selective abortions. 
The imbalance in SRB, also known as demographic masculinization, is affected by various factors like birth order, race, socioeconomic condition, religion, maternal age and literacy level, sex of the previous child, and stopping-rule behavior apart from sex selective abortions $\mathbf{s}^{4,6,7,8,9}$.

Nepal legalized abortion in the year 2002. Although sex-selective abortion is prohibited by law, data shows its prevalence in different districts and this can be taken as one of the factors affecting $\mathrm{SRB}^{10}$. Nepalese society being a patriarchal society with a dominant number of Hindu households, the preference for a male child is high ${ }^{11}$. From performing funeral rights to continuing family name and supporting the family, males are considered an asset and females a liability. SRB in Nepal is slowly on the rise from 103 in 2001 to 104 and 105 in 2006 and 2011, respectively ${ }^{12,13,14}$.

This unexpected skewing suggests millions of women are missing from the population and this is taken as an indicator of gender discrimination. The change in sex composition has tremendous effects in the future, for both males and females. While men will have difficulty finding a partner, women will suffer as a result of increased rate of gender discrimination and poor health.

The objectives of this study were to analyse the trends of SRB over the past eight years and assessing its relationship with maternal age, birth order and number of previous abortions.

\section{Materials and Methods}

This study was done at Lumbini Medical College Teaching Hospital (LMCTH), Palpa, Nepal. After ethical clearance was provided by the hospital, a retrospective assessment of birth records of all the deliveries at LMCTH between $1^{\text {st }}$ January 2008 and $31^{\text {st }}$ December 2015 (eight years) was carried out. Sex of the baby and information on each woman's age, parity and the number of abortions were recorded.

Stillbirths were excluded in the analysis in agreement with the definition of sex ratio at birth as was ambiguous genitalia. Sex ratio at birth was computed using the formula M/F $\times 100$ (where ' $M$ ' is number of male births and ' $F$ ' is number of female births.). Statistical analysis was performed using the statistical package for social sciences (SPSS, version 20.0). Pearson's chisquare test was used in ascertaining the correlation between variables with $p$-value set at $<0.05$.

\section{Results}

There were a total of 9394 deliveries over the study period. There were 38 stillbirths which were excluded and the SRB was calculated for 9356 live births. There were $5008(53.5 \%)$ male and $4350(46.4 \%)$ female live births indicating overall sex ratio at birth of 112.6. The data shows increasing number of total live births in the hospital each year and so is the sex ratio.

As depicted in Table 1, highest SRB of 115 was seen in the year 2015 whereas the highest percentage of male birth was in 2013 and 2015 (53.5\%). The mean age of women at delivery was $23.17 \pm 2.16$ years. Table 2 shows the mean maternal age, parity and abortion for male and female births. There was no statistical correlation seen between male births and maternal age ( $p$-value: 0.217$)$, parity ( $p$-value: 0.623 ) and number of abortions ( $p$-value 0.339).

The sex ratio at birth is highest (132.8) in the birth order of 4 or more and lowest (110.6) for first order birth as presented in Table 3. Thus, more the parity, more are the chances of a male birth.

Table 4 depicts the increasing trend in sex ratio with increasing birth order. This trend is seen more so from the year 2012 onwards.

Table 1: Total Deliveries and SRB

\begin{tabular}{ccccc}
\hline Year & Total deliveries & Male $\mathbf{n}(\%)$ & Female $\mathbf{n}(\%)$ & Sex ratio at birth \\
\hline 2008 & 179 & $85(47.4)$ & $94(52.6)$ & 90.4 \\
\hline 2009 & 227 & $104(45.8)$ & $123(54.2)$ & 84.5 \\
\hline 2010 & 421 & $218(51.7)$ & $203(48.3)$ & 107.3 \\
\hline 2011 & 1004 & $533(53.0)$ & $471(47.0)$ & 113.1 \\
\hline 2012 & 1299 & $686(52.8)$ & $613(47.2)$ & 111.9 \\
\hline 2013 & 1550 & $830(53.5)$ & $720(46.5)$ & 115.2 \\
\hline 2014 & 2270 & $1212(53.3)$ & $1058(46.7)$ & 114.5 \\
\hline 2015 & 2408 & $1290(53.5)$ & $1118(46.5)$ & 115.3 \\
\hline Total & 9358 & 4958 & 4400 & 112.6 \\
\hline
\end{tabular}


Table 2: Gender distribution by maternal age and birth order.

\begin{tabular}{ccc}
\hline & Male births & Female births \\
\hline Mean maternal age & $23.25 \pm 4.80$ & $23.10 \pm 4.24$ \\
\hline Mean birth order & $1.58 \pm 0.93$ & $1.55 \pm 0.92$ \\
\hline Mean number of abortions & $0.17 \pm 0.47$ & $0.14 \pm 0.42$ \\
\hline
\end{tabular}

Table 3: SRB in relation to birth order

\begin{tabular}{ccccc}
\hline & $\mathbf{1}^{\text {st }}$ order birth $\mathbf{n}(\%)$ & $\mathbf{2}^{\text {nd }}$ order birth $\mathbf{n}(\%)$ & $\mathbf{3}^{\text {rd }}$ order birth $\mathbf{n}(\%)$ & $\mathbf{2}$ order birth $\mathbf{n}(\%)$ \\
\hline Total & $5834(100)$ & $2412(100)$ & $779(100)$ & $333(100)$ \\
\hline Male & $3064(52.5)$ & $1296(53.7)$ & $418(53.6)$ & $190(57)$ \\
Female & $2770(47.5)$ & $1116(46.3)$ & $361(46.3)$ & $143(43)$ \\
\hline SRB & 110.6 & 116.1 & 115.7 & 132.8 \\
\hline
\end{tabular}

Table 4: SRB in relation to birth order by period of delivery

\begin{tabular}{ccccc}
\hline Year & SRB for $\mathbf{1}^{\text {st }}$ order birth & SRB for $\mathbf{2}^{\text {nd }}$ order birth & SRB for $\mathbf{3}^{\text {rd }}$ order birth & SRB for $\geq \mathbf{4}$ order birth \\
\hline 2008 & 94.1 & 122.2 & 120.1 & 140.3 \\
\hline 2009 & 80.2 & 100.7 & 95.2 & 122.3 \\
\hline 2010 & 116.4 & 114.8 & 121.5 & 127.1 \\
\hline 2011 & 111.3 & 100.2 & 100.3 & 130.6 \\
\hline 2012 & 107.5 & 105.6 & 111.7 & 123.5 \\
\hline 2013 & 113.8 & 117.2 & 125.9 & 129.8 \\
\hline 2014 & 117.1 & 114.1 & 120.8 & 122.1 \\
\hline 2015 & 110.3 & 119.1 & 121.2 & 138.2 \\
\hline
\end{tabular}

\section{Discussion}

This study, done from data collected over past eight years, highlighted the decreasing number of female births amongst hospital deliveries. This finding was consistent with another study done in a tertiary care hospital in Kathmandu, from 2003 to $2008^{15}$. Hospital based studies done in other Asian cities like Delhi and Hongkong also showed increasing male birth through 2006-20104,8. The overall sex ratio was unbalanced with inclination towards male. This study showed that this trend has also been continuing in this district of western Nepal.

One of the main reasons for this increased number of male births could be the preference for sons which is high in Nepalese families. Sex-selective abortion, though illegal, is prevalent in many districts of $\mathrm{Nepal}^{16}$. This compounded by the fact of easy availability of sexdetermining tools, the reason for skewing towards male would be sex-selective abortion.

Secondly, the increased numbers of male deliveries in a hospital could be the mothers' knowledge beforehand that they were carrying a male baby and therefore came to the hospital for safe birth; however, this can be clarified only after comparing this data with sex ratio among home deliveries and deliveries in government hospitals.
Palpa district has increasing male births with SRB of 87.16 in 2001 to 91.13 in $2011^{12,14}$. This study showed the trend of disappearing daughters continued in hospital deliveries. Though data on sex selective abortions in Palpa district was unavailable, being adjacent to Rupandehi district which has SRB of 132.7 , sex selective abortions could be a plausible reason for this district as well ${ }^{12}$.

Data revealed that women are more concerned about the sex of a child after first birth ${ }^{10}$. This study also showed an increase in male birth with the rise in birth order.

Traditional beliefs combined with declining fertility of Nepalese women have put significant pressure on having a male child. This was the reason for higher rate of sex-selective abortions in multiparas ${ }^{10}$. Nevertheless, this study lacked information on assisted reproduction and prenatal sex determination which could be other reason for female feticide, particularly in multiparous women.

In contrast to a ten-year study done in Nigeria ${ }^{17}$, this study found no significant relation between maternal age, mean birth order and sex of the child. Also, there was no significant relation between the number of abortions and sex ratio. This clearly suggests that there was underreporting of sex selective abortions or abortions 
in general. Amongst women with history of abortions, we were unable to differentiate between induced or spontaneous abortions and weather they were first or second trimester abortions because of retrospective nature of this study. Retrieval of that history would be useful in determining sex selective abortion as the direct cause of skewing of SRB.

Consequences of increasing male members have high implications, especially in a patriarchal society like Nepal. This study indicated towards a rise in the pre-existing discrimination, thus we may assume that participation of women in all aspects of development will further decrease, which may directly influence the stability and further development of our country.

SRB is still within acceptable range in most districts in Nepal despite prevalence of sex selection. Considering this and given the fact that SRB only

\section{References}

1. Hesketh $\mathrm{T}$, Xing WZ. Abnormal sex ratio in human populations: causes and consequences. Proc Natl Acad Sci 2006;103(36):13271-75.

2. WHO. Preventing gender-based sex selection: an interagency statement - OHCHR, UNFPA, UNICEF, UN Women and WHO. Geneva: World Health Organization; 2011

3. Zhu WX, Li L, Hesketh T. China's excess males, sex selective abortion, and one child policy: analysis of data from 2005 national intercensus survey. BMJ 2009;338:bl211. http://www.bmj.com/content/338/bmj. b1211.full

4. Tse WC, Leung KY, Hung BK. Trend of sex ratio at birth in a public hospital in Hong Kong from 2001 to 2010. Hong Kong Med J 2013;19(4):305-10.

5. Agnihotri SB. Missing females: a disaggregated analysis. Econ Polit Wkly 1995;30(33):2074-84.

6. Teitelbaum MS. Factors affecting the sex ratio in large populations. J Biosoc Sci 1970;2:61-7.

7. Mathews TJ, Hamilton BE. Trend analysis of the sex ratio at birth in the United States. Natl Vital Stat Rep 2005;53:1-17.

8. Manchanda S, Saikia B, Gupta N, Chowdhary S, Puliyel JM. Sex ratio at birth in India, its relation to birth order, sex of previous children and use of indigenous medicine. PLoS ONE 2011;6(6):e20097. doi:10.1371/ journal.pone.0020097.

9. Gupta SK, Pal DK, Tiwari R, Gupta P, Agrawal L, Sarawagi R. A descriptive study on the sex ratio at birth in institutional deliveries at Jabalpur, Madhya Pradesh, India. J Clin Diagn Res 2011;5(6):1219-23. declines after 5 to 10 years of sex selection ${ }^{18}$, additional research exploring social, cultural and economic reasons of decreasing female births in Palpa and surrounding districts is required as a result potential programs which can reverse this trend can be implemented.

\section{Conclusion}

There was a changing trend of sex ratio in hospital deliveries with a skewing towards male birth in 20082015. Notably, no significant relation was found between maternal age, number of abortions, mean birth order and sex of the child.

\section{Recommendations}

In future studies, authors recommend that SRB in relation to the sex of the antecedent birth should be accounted along with social, cultural and economic factors affecting it.

10. Frost MD, Puri $M$, Hinde PRA. Falling sex ratios and emerging evidence of sex-selective abortion in Nepal: evidence from nationally representative survey data. BMJ Open 2013;3:e002612. doi:10.1136/ bmjopen-2013-002612.

11. Leone T, Matthews Z, Zuanna GD. Impact and determinants of sex preference in Nepal. Int Fam Plan Perspect 2003;29(2):69-75.

12. Ministry of Health and Population (MOHP) [Nepal], ERA N, INC. II. Nepal demographic and health survey 2011. Kathmandu, Nepal: Ministry of Health and Population, New ERA, and ICF International, 2012.

13. Ministry of Health and Population (MOHP) [Nepal], New ERA, and Macro International Inc. Nepal Demographic and Health Survey 2006. Kathmandu, Nepal: Ministry of Health and Population, New ERA, and Macro International Inc, 2007.

14. Ministry of Health [Nepal], New ERA, and ORC Macro. Nepal Demographic and Health Survey 2001. Calverton, Maryland, USA: Family Health Division, Ministry of Health; New ERA; and ORC Macro, 2002.

15. Adhikari N, Ghimire A, Ansari I. Sex preference in urban Nepal. J Instit Med 2008;30:19-23.

16. Lamichhane $P$ et al. Sex-Selective Abortion in Nepal: A Qualitative Study of Health Workers' Perspectives. WHI 2011;21:S37-41

17. Onyiriuka AN, Ikeanyi EM. Sex Ratio at Birth: A Retrospective Audit of the Birth Records of a Nigerian Hospital. NJOG 2015;19(1):85-88

18. SM George. Millions of missing girls: from fetal sexing to high technology sex selection in India. Prenat Diagn 2006;26:604-609. 